\title{
Life prediction for spillway facility side wall
}

\author{
Asror Yangiev ${ }^{*}$, Anvar Ashrabov² and Oybek Muratov ${ }^{1}$ \\ ${ }^{1}$ Tashkent Institute of Irrigation and Agricultural Mechanization Engineers, Tashkent, Uzbekistan \\ ${ }^{2}$ Tashkent Institute of Design, Construction \& Maintenance of Automotive Roads, Tashkent, \\ Uzbekistan
}

\begin{abstract}
This article includes the analytical assessment of the durability and remaining life of the I-st category reinforced concrete structures by the fracture mechanics approaches, the prediction is based on the consideration of temporal changes in the structural features of a particular type of concrete. The main purpose of this work is to determine the durability of reinforced concrete structures and the remaining life of the spillway and components in the implemented modes and operating conditions that ensure their safe operation and environmental protection. When predicting the durability of the spillway reinforced concrete structures, each structure is considered as a component of the structure behavior scheme. The result of the durability predictions is presented in years, which can eventually determine the remaining life of the structural component of spillway.
\end{abstract}

\section{Introduction}

Major part of building constructions in the complex of hydraulic structures is made of reinforced concrete. For a safe operation of reinforced concrete structures of water discharge facilities it is very important to assess their technical condition. Reliability of spillway structures is a guarantee of trouble-free operation of the hydraulic structure.

The reinforced concrete structures (monolithic, precast-monolithic and prefabricated) used in water discharge facilities have different functions: they are load bearing and fencing structures, take up different kinds of mechanical and thermal loads [1]. There are requirements for their strength, reliability and durability [2]. Like other spillway components, the most important components and structures require life characteristics management. The purpose of the work is to assess the operational reliability of the structure and components of the water discharge facility of the Tuyabuguz reservoir. Water discharge facilities belong to $\mathrm{K}_{\mathrm{I}}$ category. These types of facilities, in addition to the perception of force and technological impacts, perform functions of environment and population protection [3]. The I-st category reinforced concrete structures must have a sufficient bearing capacity, rigidity, durability[4,6].

Assessment of the technical condition and remaining life of the components and spillway structures should be made with due consideration of the classification of reinforced concrete structures and the construction of reservoir, as well as the category of responsibility for safety.

\footnotetext{
* Corresponding author: asiauz@yandex.ru
} 


\section{Methods}

The maximum and minimum temperatures of the cold and warm periods of the year are used in calculations, rather than their average values. This will help eventually have some margin. Weather stations' data were used in the studies $[5,6]$. The concrete structure is a determinant of its durability, so the parameters of the concrete crack resistance, critical stress intensity factors, structurally dependent integral characteristics are used in calculations. The studies $[7,9,10]$ include the calculations of the concrete crack resistance parameters.

The limit value of the stress intensity factor $K_{I C}^{c r}$ for a given composition of the concrete is calculated using the formula obtained as a result of multi-factor analysis:

$$
K_{I C}^{c r}=-0,0148+0,0011 R a g+0,1330 \text { (Ц/В) }+0,0058 R c-0,0082 W b-
$$
$0,5825 \mathrm{Kag}$

where: $R_{a g}$ - strength of coarse aggregate; C/W - cement/water ratio; $R_{c}$ - cement activity, $W_{b}$ - concrete moisture level (depends on the humidity of $W$ operating environment and water content in the original composition of concrete).

Over time, the limit value of the stress intensity factor decreases under climatic and other effects [8].

The maximum stress in the side wall concrete is determined taking into account the formation of opening-mode macro crack at the outer side wall. The critical crack $l_{c r c}^{c r}$ length is calculated using the formula:

$$
l_{c r c}^{c r}=\frac{4 K_{I C}^{c r}}{R_{b} \sqrt{\pi h}}+\delta
$$

where: $h$ - thickness of the side wall; $\delta$ - thickness of the concrete protective layer.

Then, according to the fracture mechanics principles, the maximum possible stresses in the concrete of the outer layer, taking into account the scheme of external load application and reinforcement, shall bedetermined as follows:

$$
\sigma_{b}=\left(-\frac{4 * 2 * K_{I C}^{S t} A_{S}}{K_{c r c} \sqrt{0,0625 \pi d}}+N\right) \frac{l_{\operatorname{crc}} / \delta}{b h}
$$

where: $K_{I C}^{s t}$-critical stress intensity factor of the steel, $A_{s}$ - area of reinforcement per meter run, $K_{c r c}$ the factor that takes into account the stress redistribution in the reinforcement steel when the crack is formed, $d$ - diameter of the reinforcement steel.

Next, the stress intensity factors values for five categories of various defects in the concrete structure shall be determined based on the above distribution. The stress intensity factors values are used in the studies $[7,8]$. 
Table 1. Stress intensity factors taking into account the content of voids, capillaries and cracks in cement stone

\begin{tabular}{|c|c|c|c|c|c|}
\hline \multirow[t]{3}{*}{\begin{tabular}{|c|} 
Pores \\
content \\
$\mathrm{p}_{1} \ldots$ \\
$\mathrm{p}_{5}, \%$ \\
\end{tabular}} & 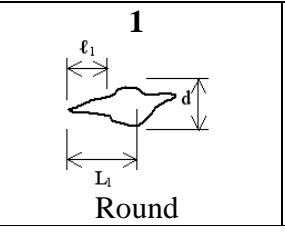 & $\underbrace{2}_{\substack{k_{\mathrm{L}_{2}}>\\
\text { Ellipsoid }}}$ & $\underset{\substack{L_{3} \\
\text { Crack-shaped }}}{\substack{(100 \div 1000) d \\
d}}$ & \multirow[t]{3}{*}{$\underset{\substack{\mathrm{L}_{4} \\
\text { Edge }}}{4}$} & \multirow{2}{*}{ 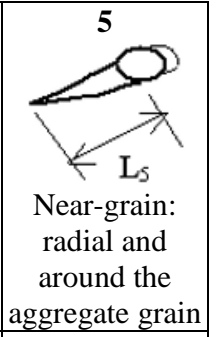 } \\
\hline & \multicolumn{3}{|c|}{ closed } & & \\
\hline & $K_{\mathrm{IC}}=A p \sqrt{\pi L(1+d}$ & $\overline{\left.\boldsymbol{K}_{\text {II }}\right)}=B p \sqrt{\pi L(a+}$ & $\begin{array}{l}\overline{\left.L_{2}^{K}\right) \mathrm{C}}=C p \sqrt{\pi L_{3}} \\
K_{\text {IIC }}=C \tau \sqrt{\pi L_{3}}\end{array}$ & & $\begin{array}{l}{ }_{4} K_{\mathrm{IC}}=E p \sqrt{\pi L_{5} 12} \\
K_{\mathrm{IIC}}=E \tau \sqrt{\pi L_{5} / 2}\end{array}$ \\
\hline$k_{i, j}$ & 0.19 & 0.15 & 0.20 & 0.04 & $0.21+0.21$ \\
\hline & A & B & $\mathrm{C}$ & $\mathrm{D}$ & $\mathrm{E}$ \\
\hline 5 & 1.733 & 1.0550 & $1.0122 / 1.0205$ & $\begin{array}{c}0.2303 / 0.200 \\
4\end{array}$ & $0.643 / 0.060$ \\
\hline 10 & 1.912 & 1.1003 & $1.0212 / 1.0417$ & \begin{tabular}{|c}
$0.3116 / 0.199$ \\
7 \\
\end{tabular} & $0.651 / 0.061$ \\
\hline 15 & 2.067 & 1.2794 & $1.0480 / 1.0630$ & \begin{tabular}{|c}
$0.3992 / 0.190$ \\
1 \\
\end{tabular} & $0.657 / 0.063$ \\
\hline 20 & 2.235 & 1.4212 & $1.0647 / 1.0890$ & $\begin{array}{c}0.4570 / 0.176 \\
2\end{array}$ & $0.682 / 0.068$ \\
\hline 25 & 2.506 & 1.6517 & $1.1010 / 1.1812$ & $\begin{array}{c}0.5640 / 0.159 \\
2\end{array}$ & $0.701 / 0.072$ \\
\hline 30 & 2.923 & 1.8432 & $1.1535 / 1.2810$ & $\begin{array}{c}0.6810 / 0.144 \\
6\end{array}$ & $0.793 / 0.081$ \\
\hline 35 & 3.084 & 2.0020 & $1.4032 / 1.4216$ & $\begin{array}{c}0.7632 / 0.141 \\
0\end{array}$ & $0.854 / 0.087$ \\
\hline 40 & 3.512 & 2.1760 & $1.5547 / 1.5732$ & $\begin{array}{c}0.8720 / 0.133 \\
7\end{array}$ & $0.892 / 0.092$ \\
\hline
\end{tabular}

Stress intensity factor (SIF) $K_{I}$ is determined for closed defects of concrete structure (1, $2,3)$ :

In winter:

$K_{I, W}^{(1,2,3)}=\frac{4 \sqrt{\pi} \cos \theta\left(7,6-0,02 T_{W}\right)}{\sqrt{l_{c, 1}\left(1-0,25\left(1-0,01 W_{W}\right)^{2}\right)}}+0,07\left(0,0003-0,000008 T_{W}\right) * \Delta T E_{i} \sqrt{\pi l_{c, 1}}[1-$

$\left.\left(\frac{2}{\pi}\right) \arcsin \left(\frac{b_{c}^{W}}{l_{c, 1}}\right)\right]+\alpha_{t, m} \Delta T E_{m} \sqrt{\pi l_{c, 1}}$

In summer:

$K_{I, S}^{(1,2,3)}=\frac{4 \sqrt{\pi} \cos \theta\left(7,6-0,02 T_{S}\right)}{\sqrt{l_{c, 1}\left(1-0,25\left(1-0,01 W_{S}\right)^{2}\right)}}+\frac{4 \sqrt{\pi} * \cos \theta\left(7,6-0,02 T_{S}\right)}{\sqrt{l_{c, 1}-b_{c}^{2}}-\left(0,0003-0,000008 T_{S}\right) \Delta T E_{W} \sqrt{\pi l_{c, 1}}\left[1-\left(\frac{2}{\pi}\right) \arcsin \left(\frac{b_{c}^{S}}{l_{c, 1}}\right)\right]}+$

$\alpha_{t, m} \Delta T E_{m} \sqrt{\pi l_{c, 1}}$

where: $\quad b_{c}^{W}=l_{c, 1}\left(1-0,01 W_{b}\right) / 2 ; \quad b_{c}^{s}=l_{c}\left(1-0,01 W_{s}\right) / 2 ; \quad W_{s}=\frac{W}{100}+\frac{B}{68}$

$\theta$ - contact angle;

$E_{m}$ - modulus of matrix elasticity;

$E_{i}$ - modulus of ice elasticity;

$T_{W} ; T_{S}$ - air temperature in winter/summer;

$l_{C, 1}$ - characteristic dimension of the structure closed defect; 
$\alpha_{t, m}$ - line expansion coefficient of the cement stone matrix.

Determined (SIF) $K_{I}^{4}$ for the 4th type edge crack:

In winter:

$$
\begin{aligned}
& K_{I, W}^{4}=2 \sqrt{2 \pi} * \cos \theta\left(7,6-0,02 T_{w}\right) \sqrt{c} * \sqrt{l_{c, 2}\left(1-\frac{b_{c}^{W}}{l_{c, 2}}\right)^{c}}+\left(0,0003+0,000008 T_{W}\right) * \\
& * \Delta T E_{i} \sqrt{l_{c, 2} / \pi} \arcsin \left(b_{c}^{W} / l_{c, 2}\right) *\left(1+f\left(l_{c, 2}, b_{c}^{W}\right)\right)+1,12 \alpha_{t, m} \Delta T E_{m} \sqrt{\pi l_{c, 2}}
\end{aligned}
$$

In summer:

$$
\begin{gathered}
K_{I, s}^{4}=2 \sqrt{2 \pi} * \cos \theta\left(7,6-0,02 T_{s}\right) \sqrt{c} * \sqrt{l_{c, 2}\left(1-\frac{b_{c}^{s}}{l_{c, 2}}\right)^{c}}+2\left(0,00007+0,000008 T_{s}\right) * \\
* \Delta T E_{w} \sqrt{l_{c, 2} / \pi} \arcsin \left(b_{c}^{s} / l_{c, 2}\right) *\left(1+f\left(l_{c, 2}, b_{c}^{s}\right)\right)+1,12 \alpha_{t, m} \Delta T E_{m} \sqrt{\pi l_{c, 2}} \\
\text { where: } f\left(l_{c, 2} b_{c}^{w}\right)=0,1215\left(1-b_{c}^{w} / l_{c, 2}\right) ; f\left(l_{c, 2} b_{c}^{s}\right)=0,1215\left(1-b_{c}^{s} / l_{c, 2}\right) \\
\mathrm{c}=2 \pi^{2} /\left(\pi^{2}-4\right)
\end{gathered}
$$

$l_{C, 2}$-characteristic dimension of the structure edge defect;

$\alpha_{t, m}$-line expansion coefficient of the cement stone matrix; $E_{w}$-modulus of water elasticity.

Determined (SIF) $K_{I}^{5}$ for the 4 th type near-grain crack:

First, the value $P$ of the internal force around the aggregate grain shall be determined:

- for the first temperature range $\left(\mathrm{T}<0^{\circ} \mathrm{C}\right)$

$$
P_{W}=\left[2\left(0,0003-0,000008 T_{W}\right) \Delta T E_{i}\left(\frac{l_{c, 1}}{2-b_{c}^{W}}\right)+\alpha_{t, m} E_{m} l_{c, 1} g\right] l_{c, 1} a_{c, 1}
$$

- for the second temperature range (positive temperatures):

$$
\begin{aligned}
& P_{S}=\left[2 \pi \cos \theta\left(7,6-0,02 T_{s}\right)+\alpha_{t, m} \Delta T E_{m} l_{c, 1} g-2\left(0,00007-0,000008 T_{s}\right) *\right. \\
& \left.\Delta T E_{W} g\left(\frac{l_{c, 1}}{2-b_{c}^{s}}\right)\right] 4,1 l_{c, 1} a_{c, 1}
\end{aligned}
$$

where: $a_{c, 1}=l_{c, 1} / 100 ; \quad g=\left(1.7+14 \alpha_{o}\right) l_{c r c} /(M-2 R)$

$R$ - coarse aggregate grains radius,

$\alpha_{o}$ - ratio of grain and matrix shear modulus.

Then, the stress intensity factor (SIF) $K_{I}^{5}$ of the 5 th type radial near-grain crack in winter and in summer shall be determined by the following formulas:

in winter:

in summer:

$$
K_{I, W}^{5,1}=P_{W} \sqrt{\pi l_{c r c}}\left\{\frac{[1-\alpha(r)] f\left(l_{c r c}, R\right)(M-R)^{2}}{\left[(M+R)^{2}-r^{2}\right]}\right\}(1+g)
$$

where: $r=l_{c r c}+R$;

$$
K_{I, S}^{5,1}=P_{S} \sqrt{\pi l_{c r c}}\left\{\frac{[1-\alpha(r)] f\left(l_{c r c}, R\right)(M-R)^{2}}{\left[(M+R)^{2}-r^{2}\right]}\right\}(1+g)
$$

$$
\begin{gathered}
\alpha(r)=2\left(1-\mu_{1}\right) r /\left\{\left(r^{2}+\left(1-2 \mu_{1}\right)(M-R)^{2}+\left[(M-R)^{2}-r^{2}\right]\left(1-\mu_{2}\right)^{2}(M-R) E_{a g} /\right.\right. \\
{\left[\left(1+\mu_{1}\right)\left(M-R-l_{c r c}\right) \cdot E_{m}\right\}=5,1 \cdot 10^{-3} ;}
\end{gathered}
$$

Poison's ratio $\mu_{1} ; \mu_{2}$.

$$
f\left(l_{c r c}, R\right)=2.26-0.15 l_{c r c} / R \text {. }
$$

For the cracks located around the aggregate grain: (refer to Table 1) in winter:

$$
K_{I, W}^{5,2}=2 * 20 P_{W}(1+\alpha) \sqrt{\pi R \sin \theta} * \frac{\left\{G_{1}\left(1+æ_{1}\right)\left[G_{1}\left(1+\mathfrak{1}_{1}\right)+G_{2}\left(1+\mathfrak{x}_{2}\right)\right] e^{\beta(\theta+\pi)}\right\}}{\left\{\left(G_{1}+G_{2} \mathfrak{x}_{2}\right)\left[G_{2}\left(1+\mathfrak{x}_{2}\right)+2 G_{1}\left(1+\mathfrak{x}_{1}\right)\right]-G_{2}\left(1+\mathfrak{x}_{2}\right)\left(G_{2}+G_{1} \mathfrak{1}_{1}\right)\left(\cos \theta-2 P_{W} \sin \theta\right) e^{-2 \beta \theta}\right\}}
$$


In summer:

$$
K_{I, S}^{5,2}=20 P_{S}(1+\alpha) * \sqrt{\pi R \sin \theta} * \frac{\left\{G_{1}\left(1+\mathfrak{x}_{1}\right)\left[G_{1}\left(1+\mathfrak{x}_{1}\right)+G_{2}\left(1+\mathfrak{x}_{2}\right)\right]\right]^{\beta(\theta+\pi)\}}}{\left\{\left(G_{1}+G_{2} \mathfrak{x}_{2}\right)\left[G_{2}\left(1+\mathfrak{x}_{2}\right)+2 G_{1}\left(1+\mathfrak{x}_{1}\right)\right]-G_{2}\left(1+\mathfrak{x}_{2}\right)\left(G_{2}+G_{1} \mathfrak{x}_{1}\right)\left(\cos \theta-2 P_{S} \sin \theta\right) e^{-2 \beta \theta}\right\}}
$$

$$
\begin{aligned}
& \text { where: } \mathfrak{x}_{1}=\frac{\left(3-\mu_{1}\right)}{\left(1+\mu_{1}\right)} ; \quad æ_{2}=\frac{\left(3-\mu_{2}\right)}{\left(1+\mu_{2}\right)} \\
& \beta=\ln \alpha / 2 \pi ; \\
& \alpha=\left(G_{1}+G_{2} * æ_{2}\right) *\left(G_{2}+G_{1} * æ_{1}\right) .
\end{aligned}
$$

The durability of reinforced concrete structure in terms of temperature and humidity impacts depends on the number of structural defects in concrete and changes in physical and mechanical properties in concrete and reinforcement caused by impacts. The works $[9,10]$ cover the studies of physical and mechanical properties of concrete and reinforcement.

Defects in the concrete structure, both initial and developing as a result of force and non-force impacts, are divided into 5 main types (Table 1). The content of 1,2, 3 and 4 type voids, pores and cracks depends on the concrete porosity, and the content of 5 type voids, pores and cracks depends on the volume content of small or coarse aggregate grains.

The volume content of each type of voids, pores and cracks depends on the porosity of the material and the volume content of the aggregate in the concrete and is determined by physical and chemical studies of the concrete sample. If the durability is predicted without production of cores and prototypes, then refer to (Table 2).

Table 2. The number of different defects per the concrete volume unit depending on the concrete porosity and the volume content of the aggregate

\begin{tabular}{|c|c|c|c|c|c|c|}
\hline \multirow{2}{*}{$\begin{array}{c}\text { Porosity of } \\
\text { concrete }\end{array}$} & $\begin{array}{c}\text { Tolume content } \\
\text { of aggregate }\end{array}$ & $\mathbf{1}$ & $\mathbf{2}$ & $\mathbf{3}$ & $\mathbf{4}$ & $\mathbf{5}$ \\
\cline { 2 - 7 } & \multicolumn{6}{|c|}{ Number of defects per the concrete volume unit, \% } \\
\hline \multirow{3}{*}{0.08} & 0.0 & 29 & 26 & 26 & 9 & 0 \\
\cline { 2 - 7 } & 0.2 & 23 & 23 & 23 & 15 & 16 \\
\cline { 2 - 7 } & 0.4 & 19 & 15 & 23 & 14 & 32 \\
\hline \multirow{3}{*}{0.10} & 0.0 & 28 & 27 & 25 & 20 & 0 \\
\cline { 2 - 7 } & 0.2 & 26 & 20 & 20 & 16 & 18 \\
\hline \multirow{3}{*}{0.12} & 0.4 & 20 & 18 & 16 & 10 & 36 \\
\cline { 2 - 7 } & 0.0 & 27 & 23 & 25 & 25 & 0 \\
\cline { 2 - 7 } & 0.2 & 22 & 18 & 21 & 19 & 20 \\
\hline
\end{tabular}

Upon finding the values of stress intensity factors for each type of voids in temperature and humidity impacts in the cold $K_{1, W}^{T W}$ and warm $K_{1, S}^{T W}$ season and caused by force loads $K_{1}^{N}$, we can calculate the total stress intensity factors.

Total stress intensity factor will be:

In winter:

In summer:

$$
K_{I, W}=\sum_{i=1}^{5} K_{i, W}^{i, j} * k_{i, j}
$$

$$
K_{I, S}=\sum_{i=1}^{5} K_{i, S}^{i, j} * k_{i, j}
$$


where: $k_{i, j^{-}}$the number of a crack-like defect of the total number of micro-and macrodamages (Table 1).

The durability of concrete of the reinforced concrete structures or the period within which the structural parameters of the concrete of the accepted composition will reach the limit values, will be equal to:

the result is shown in years.

$$
t=2\left(K_{I}^{c r}-K_{I}^{N}\right) /\left|K_{I, W}^{T W}-K_{I, S}^{T W}\right| \Psi
$$

where: $\psi$ is the concentration criterion of the damage measure.

\section{Results}

The spillway side wall is made of M200 concrete. Concrete class (B15) of the following composition per $1 \mathrm{~m}^{3}$ of concrete composition: C - $286 \mathrm{~kg}, \mathrm{G}-1,080 \mathrm{~kg}, \mathrm{~S}-795 \mathrm{~kg}, \mathrm{~W}-$ 210 1/kg, C/W - 0.73 .

The thickness of the spillway side wall - 0.4m, height - 5m, length - $16.5 \mathrm{~m}$. Reinforcement over the wall thickness: 4 reinforcement cages, $\mathrm{d}=16$, AIII spaced at intervals of $200 \mathrm{~mm}$. The concrete protective layer is $30 \mathrm{~mm}$.

The outer part of the side wall of spillway flume is exposed to the following impacts temperature and humidity.

Climatic (peak) parameters of the reservoir (Tuyabuguz) area:

- in winter: temperature $\left(-10^{\circ} \mathrm{C}\right)$, air humidity $-75 \%$;

- in summer: temperature $\left(+40^{\circ} \mathrm{C}\right)$, air humidity $-55 \%$.

It is required to determine the remaining life of concrete of the spillway side wall, which is in operation for 56 years.

SIF $K_{I C}^{c r}$ limit value for a given composition of concrete is determined as follows (1).

$K_{I C}^{c r}=-0.0148+0.0011 \cdot 117.7+0.1330(286 / 210)+0.0058 \cdot 50-0.0082 \cdot 3.84-$

$0.5825 \cdot 0.496=0.844 \mathrm{MPa} \cdot \mathrm{m}^{1 / 2}$. This is the maximum possible SIF value.

where: $R_{a g}=117.7 \mathrm{MPa}$ - strength of coarse aggregate (Gravel); Tests were performed by the laboratory of JSC "Hydroproject"; fraction diameters were selected as 5 to $10 \mathrm{~mm}$. The compressive strength is equal to $1 \mathrm{ton} / \mathrm{cm}^{2}$. R=1200 $\mathrm{kgf} / \mathrm{cm}^{2}$.

$\mathrm{C} / \mathrm{W}=1.36$

$R_{c}=50 \mathrm{MPa}$, the cement activity (500 grade Portland cement produced by the Navoi plant was adopted as the relevant option); when M200 is used, PC500 is permitted, provided that hardening period is 28 days [12]. When using gravel, the coefficient is 0.96 .

Concrete moisture level:

$W_{b}=W / 100+\mathrm{B} / 68=75 / 100+210 / 68=3.84 \%$;

$K_{a g}=0.496 \mathrm{1} / \mathrm{m}^{3} \cdot 10^{-3}$ quantity of aggregate per concrete volume unit, when the bulk volume weight of gravel is $1,600 \mathrm{~kg} / \mathrm{m}^{3}$.

Over time, the limit value of the SIF decreases under climatic and other effects.

The total porosity of concrete is:

$$
\mathrm{P}=(\mathrm{W} / \mathrm{C}-0.21 \alpha) \mathrm{C} / 1000=(0.73-0.21 \cdot 0.7) 286 / 1000=0.16 \%
$$

where: $\alpha=0.7$ - degree of cement hydratation;

$\mathrm{W} / \mathrm{C}=210 / 286=0.73$ - water-cement ratio.

Below there is the assessment of the initial distribution of pores and capillaries in the concrete of the spillway side wall according to the shape of defects in the structure, depending on the porosity. When the porosity $\mathrm{P}=0.16 \%$ and the quantity of aggregate per concrete volume unit $K_{a g}=0.496 \mathrm{1} / \mathrm{m}^{3} \cdot 10^{-3}$ up to the exposure of external load, the types of voids shall be distributed as follows: round - $17 \%$, ellipsoid - $13 \%$, crack-shaped - $20 \%$, edge $-8 \%$, near-grain - $42 \%$ (refer to Table 2 ). 
The maximum stress in the side wall concreteis determined taking into account the formation of opening-mode macrocrack at the outer side wall.

The critical crack $l_{c r c}^{c r}$ length is determined using the formula (2):

$$
l_{c r c}^{c r}=\frac{4 * 0,844}{34 \sqrt{3,14 * 0,4}}+0,030=0,17 m
$$

where: $h$ - the thickness of the side wall, $0.4 \mathrm{~m}$;

$\delta$ - the thickness of the concrete protective layer, 30mm;

the value $R_{b}=34 \mathrm{MPa}$ shall be determined using the pistol IPS MG 4.03.

Then, according to the fracture mechanics principles, the maximum possible stresses in the concrete of the outer layer, taking into account the scheme of external load application and reinforcement, shall bedetermined as follows (3):

$$
\sigma_{b}=\left(-\frac{4 * 2 * 27,5 * 1,01 * 10^{-3}}{1 \sqrt{0,0625 * 3,24 * 0,016}}+21,3\right) \frac{0,02 / 0,030}{5 * 0,4}=7.3 \mathrm{MPa}
$$

where: $K_{I C}^{c r}=27.5 \mathrm{MPa} \cdot \mathrm{m}^{1 / 2}$,

$A_{s}$ - area of reinforcement per meter run, (along the wall width $h$ - 4 cages),

$K_{c r c}$ the factor that takes into account the stress redistribution in the reinforcement steel when the crack is formed, $d$ - diameter of the reinforcement steel, $N=21.3 \mathrm{MN}$ according to [11].

Next, the stress intensity factors values for five categories of various defects in the concrete structure shall be determined based on the above distribution.

Using the formulas (4) and (5) we can calculate $K_{I}$ for closed defects of concrete structure $(1,2,3)$.

In winter:

$$
\begin{gathered}
K_{I, W}^{(1,2,3)}=\frac{4 \sqrt{3,14} \cos 0(7,6-0,02 * 10)}{\sqrt{1 * 10^{-3}\left(1-0,25(1-0,01 * 3,84)^{2}\right)}}+0,07(0,0003-0,000008 * 10) * 50 * \\
5000 \sqrt{3,14 * 1 * 10^{-3}} *\left[1-\left(\frac{2}{3,14}\right) \arcsin \left(\frac{4,80 * 10^{-4}}{10^{-3}}\right)\right]+0,000010 * 50 * \\
3057,4 \sqrt{3,14 * 1 * 10^{-3}}=2,62 \mathrm{MPa} * \mathrm{~m}^{1 / 2}
\end{gathered}
$$

In summer:

$$
\begin{gathered}
K_{I, S}^{(1,2,3)}= \\
\frac{4 \sqrt{3.14} \cos 0(7.6-0.02 * 50)}{\sqrt{10^{-3}\left(1-0.25(1-0.01 * 3,63)^{2}\right)}}+ \\
\frac{4 \sqrt{3,14} * \cos 0(7,6-0,02 * 40)}{\sqrt{10^{-3}-\left(4.81 * 10^{-4}\right)^{2}}-(0.0003-0.000008 * 40) * 50 * 1000 \sqrt{3.14 * 1 * 10^{-3}}\left[1-\left(\frac{2}{3.14}\right) \arcsin \left(\frac{4.81 * 10^{-4}}{10^{-3}}\right)\right]}+ \\
0.000010 * 50 * 3057.4 \sqrt{3.14 * 1 * 10^{-3}}=2.33 \mathrm{MPa} * \mathrm{~m}^{1 / 2}
\end{gathered}
$$

where:

$$
\begin{aligned}
& \quad b_{c}^{W}=\frac{10^{-3}(1-0.01 * 3,84)}{2}=4,80 * 10^{-4} ; b_{c}^{s}=\frac{10^{-3}(1-0,01 * 3,63)}{2}=4,81 * 10^{-4} ; \\
& W_{s}=\frac{55}{100}+\frac{210}{68}=3.63 \%
\end{aligned}
$$

$\theta$ - contact angle;

$E_{m}$ - modulus of matrix elasticity, calculated according to the formula:

$$
\begin{gathered}
\mathrm{E}_{\mathrm{m}}=-28720+12160 \mathrm{C} / \mathrm{W}+182.5 R_{c}= \\
-28720+12160 \cdot(286 / 210)+182.5 \cdot 50=3057.4 ;
\end{gathered}
$$

$T_{W}=-10^{\circ} \mathrm{C} ; \Delta T=10+40=50^{\circ} \mathrm{C} ; E_{i}$ - modulus of ice elasticity; $W_{b}=W_{W}=3.84 \%$.

Using the formulas (6) and (7) we can calculate $K_{I}^{4}$ for the edge crack of type 4 (refer to Table 1).

In winter:

$$
\begin{gathered}
\left.K_{I, W}^{4}=2 \sqrt{2 * 3.14} * \cos 0(7,6-0,02 * 10) \sqrt{3,36} * \sqrt{10^{-3}\left(1-\frac{4.80 * 10^{-4}}{10^{-3}}\right)}\right)^{3,36} \\
(0.0003+0.000008 * 10) * 50 * 5000 \sqrt{10^{-3} / 3.14} \arcsin \left(4.80 * 10^{-4} / 10^{-3}\right) *
\end{gathered}
$$




$$
\begin{gathered}
(1+0,06)+1,12 * 0.000010 * 50 * 3057.4 * \sqrt{3.14 * 10^{-3}}=(67.98 * 0.01)+(3.39 * \\
0.5353)+0.09=2.58 \mathrm{MPa} * \mathrm{~m}^{1 / 2}
\end{gathered}
$$

In summer:

$$
\begin{gathered}
K_{I, S}^{4}=2 \sqrt{2 * 3,14} * \cos 0(7,6-0,02 * 40) \sqrt{3,36} * \sqrt{10^{-3}\left(1-\frac{4,81 * 10^{-4}}{10^{-3}}\right)^{3,36}}+ \\
2(0,00007+0,000008 * 40) * 50 * 1000 \sqrt{10^{-3} / 3,14} \operatorname{arc~} \sin \left(4,81 * 10^{-4} / 10^{-3}\right) * \\
(1+0,063)+1,12 * 0,000010 * 50 * 3057,4 * \sqrt{3,14 * 10^{-3}}=(0,01 * 62,47)+ \\
(0,695 * 0,502 * 1,063)+0,096=1,091 \mathrm{MPa} * \mathrm{~m}^{1 / 2} \\
\text { where: } b_{c}^{W}=l_{c, 1}\left(1-0,01 W_{b}\right) / 2 ; b_{c}^{W}=\frac{10^{-3}(1-0,01 * 3,84)}{2}=4,80 * 10^{-4} \\
b_{c}^{s}=l_{c}\left(1-0,01 W_{s}\right) / 2 ; b_{c}^{s}=\frac{10^{-3}(1-0,01 * 3,63)}{2}=4,81 * 10^{-4} \\
f\left(l_{c, 2} b_{c}^{w}\right)=0,1215\left(1-4,80 * 10^{-4} / 10^{-3}\right)=0,06 \\
f\left(l_{c, 2} b_{c}^{s}\right)=0,1215\left(1-4,81 * 10^{-4} / 10^{-3}\right)=0,063 \\
\mathrm{c}=2 \pi^{2} /\left(\pi^{2}-4\right)=3.36
\end{gathered}
$$

$\alpha_{t, m}=0,000010$ - line expansion coefficient of the cement stone matrix [13].

$T_{S}=40^{\circ} \mathrm{C} ; E_{w}=1000$ modulus of water elasticity.

Using the formulas (8) and (9) we can calculate $P$ - the internal force around the aggregate grain:

- for the first temperature range $\left(\mathrm{T}<0^{\circ} \mathrm{C}\right)$

$$
\begin{gathered}
P_{W}=\left[2(0,0003-0,000008 * 10) * 50 * 5000\left(\frac{10^{-3}}{2-4,80 * 10^{-4}}\right)+0,000010 * 3057,4 *\right. \\
\left.10^{-3} * 8,98\right] * 10^{-3} * 10^{-5}=5,52 * 10^{-10} \mathrm{MN}
\end{gathered}
$$

where: $a_{c, 1}=10^{-3} / 10^{2}=10^{-5} \mathrm{~m} ; g=(1.7+14 \cdot 0.52) * 0.02 /(0.03-2 \cdot 0.01)=8.98$

$R=10 \mathrm{~mm} ; M=3 R=0.03 \mathrm{~m} ; \alpha_{o}=0.52 ; l_{c r c}=2 R=0.02 \mathrm{~m}$.

- for the second temperature range (positive temperatures):

$P_{S}=[2 \pi \cos 0(7,6-0,02 * 40)+0,000010 * 50 * 3057,4 * 0,001-2(0,00007-$

$\left.0,000008 * 40) * 50 * 1000 * 8,98\left(\frac{0,001}{2-4,81 * 10^{-4}}\right)\right] 4,1 * 10^{-3} * 10^{-5}=1,75 * 10^{-6} \mathrm{MN}$

The value for the 5th type radial near-grain crack is calculated using the formulas (10) and (11):

in winter:

$$
\begin{gathered}
K_{I, W}^{5,1}=5,52 * 10^{-10} * \sqrt{3,14 * 0,02}\left\{\frac{\left[1-5,1 * 10^{-3}\right] 1,66(0,03-0,01)^{2}}{\left[(0,03+0,01)^{2}-0,03^{2}\right]}\right\}(1+8,98)=12,25 * \\
10^{-10} \mathrm{MPa} * \mathrm{~m}^{1 / 2}
\end{gathered}
$$

in summer:

$$
\begin{gathered}
K_{I, S}^{5,1}=1,75 * 10^{-6} * \sqrt{3,14 * 0,02}\left\{\frac{\left[1-5,1 * 10^{-3}\right] * 1,66 *(0,03-0,01)^{2}}{\left[(0,03+0,01)^{2}-0,03^{2}\right]}\right\}(1+8,98)=0,41 * \\
10^{-5} \mathrm{MPa} * \mathrm{~m}^{1 / 2} \\
\text { where: } r=l_{c r c}+R=0.02+0.01=0.03 ; \alpha(r)=5.1 \cdot 10^{-3} ;
\end{gathered}
$$

Poison's ratio $\mu_{1}=0,2 ; \mu_{2}=0,16$.

$$
f\left(l_{c r c}, R\right)=2.26-0.15 \cdot 4=1.66
$$

Stress intensity factors for cracks around the aggregate grain shall be calculated using the formulas (12) and (13):

in winter:

$$
\begin{gathered}
K_{,, W}^{5,2}= \\
2 * 20 * 5,52 * 10^{-10} *\left(1+4,15 * 10^{9}\right) * \sqrt{3,14 * 0,01 \sin 120} * \\
\left\{13560(1+2,3)[13560(1+2,3)+27500(1+2,4)] e^{3,51\left(\frac{5\left(\frac{5}{6}, 14\right.}{6}+3,14\right)}\right\}
\end{gathered}
$$

$\overline{\left\{(13560+27500 * 2,4)[27500(1+2,4)+2 * 13560(1+2,3)]-27500(1+2,4)(27500+13560 * 2,3)\left(\cos 120-2 * 5,52 * 10^{-10} \sin 120\right) e^{-2 * 3,51 * \frac{5 * 3,14}{6}}\right\}}=$

$$
8,32 * 10^{-5} \mathrm{MPa} * \mathrm{~m}^{1 / 2}
$$


In summer:

$$
\begin{aligned}
& K_{I, S}^{5,2}= \\
& 20 * 1,75 * 10^{-6} *\left(1+4,15 * 10^{9}\right) * \sqrt{3,14 * 0,01 \sin 120} * \\
& \left\{13560(1+2,3)[13560(1+2,3)+27500(1+2,4)] e^{3,51\left(\frac{5 * 3,14}{6}+3,14\right)}\right\} \\
& \overline{\left.(13560+27500 * 2,4)[27500(1+2,4)+2 * 13560(1+2,3)]-27500(1+2,4)(27500+13560 * 2,3)\left(\cos 120-2 * 1,75 * 10^{-6} \sin 120\right) e^{-2 * 3,51 * \frac{5 * 3,14}{6}}\right\}}= \\
& 1,25 \mathrm{MPa} * \mathrm{~m}^{1 / 2} \\
& \beta=\ln \left(4.15^{*} 10^{9}\right) / 2 \pi=3.52 \\
& \alpha=(27500+13560 * 2.3) *(13560+27500 * 2.08)=4.15 * 10^{9}
\end{aligned}
$$

The total stress intensity factor shall be calculated using the formulas (14) and (15):

In winter:

$$
\begin{gathered}
K_{I, W}=\sum_{i=1}^{5}(0,19+0,15+0,20) * 2,62+0,04 * 2,58+0,21 * 12,52 * 10^{-10}+ \\
0,21 * 8,32 * 10^{-5}=1,42 \mathrm{MPa} \cdot \mathrm{m}^{1 / 2}
\end{gathered}
$$

In summer:

$$
\begin{gathered}
K_{I, S}=\sum_{i=1}^{5}(0,19+0,15+0,20) * 2,33+0,04 * 1,091+0,21 * 0,41 * 10^{-5}+0,21 * \\
1,25=1,55 \mathrm{MPa} \cdot \mathrm{m}^{1 / 2}
\end{gathered}
$$

where: $k_{i, j}$ - refer to Table 1 .

The stress intensity factor under the force load shall be determined for each of the 5 types of cracks (refer to Table 1).

For round cracks:

$$
K_{I C}^{1, N}=2.34 * 7.3 \sqrt{3.14 * 10^{-5}\left(1+10^{-5} /\left(2 * 10^{-5}\right)\right)}=0.11 \mathrm{MPa} \cdot \mathrm{m}^{1 / 2}
$$

For ellipsoid cracks:

$$
K_{I C}^{2, N}=1.43 * 7.3 \sqrt{3,14\left(5 * 10^{-5}+10^{-4}\right)}=0,39 \mathrm{MPa} \cdot \mathrm{m}^{1 / 2}
$$

For crack-shaped defects:

For edge cracks:

$$
K_{I C}^{3, N}=1,0647 * 7,3 \sqrt{3,14 * 10^{-3} / 2}=0,307 \mathrm{MPa} \cdot \mathrm{m}^{1 / 2}
$$

For near-grain cracks:

$$
K_{I C}^{4, N}=0,3684 * 7,3 \sqrt{3,14 * 10^{-3}}=0,15 \mathrm{MPa} \cdot \mathrm{m}^{1 / 2}
$$

$$
K_{I C}^{4, N}=0,93 * 7,3 \sqrt{3,14 * \frac{10^{-2}}{2}}=0,85 \mathrm{MPa} \cdot \mathrm{m}^{1 / 2}
$$

So, the total stress intensity factor under the force impact is equal to:

$$
K_{I, C}^{N}=0.11+0.39+0.307+0.15+0.85=1.807 \mathrm{MPa} \cdot \mathrm{m}^{1 / 2}
$$

according to the formula (16) we can calculate the time of safe operation of the spillway fume side wall:

$$
t=\frac{2(1,807-0,844)}{|1,42-1,55|}=14 \text { years. }
$$

\section{Discussion}

The durability of reinforced concrete structures of spillways can be predicted upon the assessment of the condition of their components, structures and the construction as a whole, based on the analysis of technical documentation for the entire operational period, the results of technical inspection of the condition of reinforced concrete structures and verification calculations for the structures.

To predict the remaining life of the spillway component belonging to the K-I category of responsibility, it is necessary to obtain data on the pore structure of concrete characterizing the crack resistance of the structure component. The concrete pore structure can be determined in two ways: laboratory studies of concrete samples and theoretically. 
The works $[8,14]$ include the laboratory studies of the pore structure of concrete samples. The morphological analysis of the concrete structure of the selected samples was carried out in the laboratory. Concrete samples are taken from the most stressed area of the monolithic structure (in critical areas), where there are the maximum stresses in the reinforcement and concrete. The location of the most stressed part of the structure is determined according to the design schemes of operational loads application, from the project documentation. Researchers used a theoretical approach in the works $[2,8,15,16,17]$. It should be noted that when the theoretical approach to the assessment of the concrete pore structure is used, the results of prediction of the durability and remaining life of concrete structures will be less accurate. The theoretical analysis of the concrete pore structure includes the determination of the design strength characteristics of concrete, the type of coarse aggregate, the composition of the concrete by the mass (cement, gravel, sand, water) and water-cement ratio at the end. According to our algorithm of calculationsthe $K_{I W}$ and $K_{I S}$ intensity factors in winter and in summer vary slightly. The $K_{I C}$ stress intensity factors for 5 types of cracks under the force load are determined by calculations.According to the calculations, the long-term impact of all external factors reduces the durability of the structure, therefore, it is necessary to determine the remaining life of the spillway concrete structures. Taking into account the previous 56-year service life of the spillway it is possible to calculate the remaining life of the fume side wall in years.

\section{Conclusions}

To calculate the remaining life of the structural component of the spillway fume, which is important for the safety, of the I-st category of responsibility, the concrete fracture mechanics method was used and temporal changes of the concrete structure were accounted.The method used was based on the following basic principles and provisions that determine the durability and fracture mechanisms of concrete:

- The concrete was considered as an elastic quasi-homogeneous two-component medium consisting of a) matrix - the cement stone with structural elements of gravel and sand; b) voids, capillaries and cracks.

- All voids in the concrete structure could be considered as crack-shaped structural defects. The generation of cracks takes time, and this process can be called "concrete aging".

- The voids in the matrix were represented by a subordinate five-level system (in shape and sizes multiple of diameter; the greater the multiple, the higher the level), (refer to Table 1).

- The process of formation and shifting of cracks was considered as a result of external force and non-force impact: at the top of each crack of its level in the canonical volume of concrete the deformation and stress fields appeared andcreated the schemes of normal separation and shear.

- $K_{c i j}(\tau)$ was taken as a cumulative constant of the concrete crack resistance, its resistance to formation, accumulation in volumes and formation of main cracks of critical size. This value was was adopted as an algebraic sum of $K_{i j}$ critical values in the whole system of all levels of crack-voids filling the canonical volume to the critical concentration.

- External temperature, humidity and corrosion long-term impacts have created stress fields at the tops of crack-voids, which were taken as $D$ value, using the provisions of concrete aging theory:

$$
K_{i c}(\tau)=K_{i c}\left(\tau_{o}\right) D
$$

- The stress-strain state of the structural component of the spillway side wall depended on the size and number of structural defects and damages in concrete and 
reinforcement, intensity and modes of temperature, humidity, corrosion and force impacts.

- Cracks in the structure of concrete that developed by opening fracture mode and lateral shear mechanisms had a dominant effect on the bearing capacity of the sections of the reinforced concrete component of the spillway fume. When these cracks reached critical dimensions under the force and temperature impacts, they caused local breach of cross sections and the damage of the component as a whole, and reached the parameters of the through crack.

In this work, as there were no results of morphological analysis, the calculations were based on tabular data (Table 1 and 2) on the concrete structure, depending on the composition and porosity of the concrete, the type and volume content of the aggregate. The works $[18,19,20]$ recommend the data obtained upon the results of laboratory and morphological analysis of the concrete samples structure, taking into account the force and technological impacts.

\section{References}

1. P.I.Vasilyev, Yu.I. Kononov, Ya.N. Chirkov, Reinforced concrete structures of hydraulic constructions 86-97 (1982)

2. A.A. Ashrabov, Reliability and durability of building systems, 323-341 (2012)

3. A.A. Ashrabov, Diagnostics, testing and rehabilitation of facilities, 58-65 (2014)

4. S.N. Alekseev, F.M. Ivanov, S. Modra and P. Schissel, The durability of concrete in aggressive media, 320 (1990)

5. S.V. Aleksandrovsky, Calculations of temperature and humidity impacts for concrete and reinforced concrete structures (including creeping), 444 (1966)

6. S.V. Aleksandrovsky Durability of external enclosing structures, 332 (2004)

7. A.A. Ashrabov, O.A. Muratov, Calculation of the service life of concrete and reinforced concrete structures of hydraulic constructions based on crack resistance, In. Sc. J. Na. Man. Anth. Pr. 4, 22-30 (2014)

8. A.A. Ashrabov, New methods and models in the mechanics of reinforced concrete, 6675 (2014)

9. G.D. Shmelev, Complex engineering methodology for predicting the remaining life of reinforced concrete structures, (582 - 585). 2006.

10. L.B. Glukhov, and others, Dynamics, strength and reliability of engineering structures components, 304 (2003)

11. L.P. Trapeznikov, Temperature crack resistance of massive concrete structures, 272 (1987)

12. SNiP 5.01.23-83, (Building codes), Standard cement consumption rates for the preparation of precast concrete and monolithic concrete, reinforced concrete products and structures, 5-12 (1985)

13. SNiP 2.06.08.87, (Building codes), Concrete and reinforced concrete structures of hydraulic constructions, 3-10 (1987)

14. V.P. Chirkov, A.A. Cernant, E.A. Antropova, I.A. Begun, Service life is the basis for the design of transport systems, 60 (2000)

15. V.V. Bolotin, Methods of probability theory and reliability theory in the calculations of structures, 351 (1982)

16. V.P. Chirkov, Forecasting the crack resistance of prestressed concrete beams subject to the time factor, 21-25 (2001)

17. A.I. Vasilyev, E.A. Antropova, V.I. Shesterikov, Prediction of the service life of an exploited decking structures, 32 (1996) 
18. V.P. Chirkov, Reliability and durability of reinforced concrete structures of buildings and constructions, 86-117 (1998)

19. S.A. Reddi, Design Life of Concrete Structures, 407-415 (1997).

20. K. Many, H.D. Sreenath, Service Life Prediction and Corrosion Protection Methods in Reinforced Concrete Structures, 257- 266 (1997) 